\title{
Medical honey and the role in pediatric emergency wound management
}

\author{
Anne Weissenstein ${ }^{1}$, Gloria Villalon ${ }^{1}$, Elisabeth Luchter ${ }^{1}$, Stefan Bittmann ${ }^{{ }^{*}}$ \\ ${ }^{1}$ Ped Mind Institute (PMI), Department of Pediatrics, Medical and Finance Center, Hindenburgring 4, D-48599 Gronau, Germany
}

\section{ABSTRACT}

The use of complementary medical treatment in wound management has continued to grow throughout the world. There is a large body of evidence to support the use of honey as a wound dressing for a wide range of types of wounds. Clear guidelines for the use of honey in pediatric wound care do not exist. We present an update of present knowledge using honey as a form of complementary medicine in pediatric wound management.

Keywords: Honey; pediatric; child; wound; infection

\section{Introduction}

\subsection{Text}

We report an update on historical and general aspects of honey and the few published data concerning honey as a form of complementary and alternative medicine (CAM) used in pediatric wound management. The literature cited was found by searching the PubMed, BIOSIS, and ISI Web of Science databases for the term honey. Excluded were papers where honey was used in a mixture with other therapeutic substances.

Historical aspects of honey

Honey has a long history of use as a medical substance. Stone age paintings in several locations dating to $6000 \mathrm{BC}$ or earlier depict honey hunting, documenting human use of honey for at least 8000 years. Referencesto honey as a medicine are found in ancient scrolls, tablets and books. Sumerian clay tablets estimated to be 6200 BC, Egyptian papyri dated from 1900-1250 BC, Veda (Hindu scripture) about 5000 years old, the Holy Koran, the Talmud, both the old and new testaments of the Bible, sacred books of India, China, Persia and Egypt ${ }^{[7]}$. For example, in ancient Egypt it was used as a wound treatment and for gut conditions. Hippokrates recommended honey for pain, water and honey for thirst and a mixture of honey, water and other substances to treat acute fevers, as well as recommending it to treat ulcers $^{[8]}$. The Bible mentions the use of honey in eye problems ${ }^{[9]}$. The antibacterial property of honey was first recognized in 1892 by Van Keetal ${ }^{[34]}$.

General aspects of honey

Honey is produced by bees from plant nectars and from excretions of plant sucking insects ${ }^{[21.23]}$. Honey is a carbohydrate-rich syrup produced by bees, primarily from floral nectars. Fructose and glucose are the major components but a large number of other chemical compounds are present in small quantities ${ }^{[25.26]}$. Three aspects of the composition of honey have been identified to contribute to antibacterial activity: The low water activity inhibits microbial growth, particularly bacterial growth. The low $\mathrm{pH}$, a result of the formation of gluconic acid, also has a mild antibacterial effect and may decrease the action of proteases ${ }^{[26.66]}$. Honey is mildly acidic with a pH around 3,9.

When diluted with water, hydrogen peroxide is formed by the action of the enzyme glucose oxidase in concentrations which exhibit antibacterial effects but without cytotoxic side effects ${ }^{[27,28]}$. Purified honey is defined as obtained by purification of the honey from the comb of the bee, Apis mellifera and other species of Apis. Potassium is the major mineral present. Fructose and glucose are the two major sugars present in honey, with lesser amounts of sucrose, other disaccharides and oligosaccharides ${ }^{[23,25,26]}$. There are a range of other uncharacterized substances present in some

\footnotetext{
Copyright (C) 2018 Stefan Bittmann et al.

doi: $10.24294 /$ jpedd.v2i2.780

EnPress Publisher LLC.This work is licensed under the Creative Commons Attribution-NonCommercial 4.0 International License (CC BY-NC 4.0).

http://creativecommons.org/licenses/ by/4.0/
} 
honeys. Identified substances were syringic acid, 3,4,5-trimethoxybenzoic acid, 2-hydroxy-3-phenylpropionic acid and the flavonoid pinocembrin ${ }^{[1]}$. The chemical composition of honey varies depending on plant source, season and production methods.

Honey has been demonstrated in many studies to have antibacterial effects, attributed to the high osmolarity, low $\mathrm{pH}$, hydrogen peroxide content and content of other uncharacterized compounds ${ }^{[26,27,32]}$. When applied topically to wounds, osmosis would be expected to draw water from the wound into the honey, helping to dry the infected tissue and reduce bacterial growth. Even when diluted with water absorbed from wounds, honeys would be likely to retain a water activity sufficiently low to inhibit growth of most bacteria.

Studies on antimicrobial and antiviral activity

Honeys were categorized according to their floral source ${ }^{[2]}$. For most honey tested, destruction of peroxide-generating ability by the use of catalase was associated with loss of antibacterial activity. Manuka honey (Leptospermum scoparium) and vipers bugloss (Echium vulgare) were the only honey tested that retained significant antibacterial activity. In another study, complete inhibition of growth of S. aureus was achieved at a manuka honey concentration of $1.8 \%$ compared to $4.9 \%$ for other honeys ${ }^{[3]}$. Despite the differences observed with different pathogens and honey types, the study demonstrated that a range of honey have bacteriostatic effects at concentrations likely to be achieved when honey is applied topically to the wounds ${ }^{[3]}$. Sudanese honeys were studied by White ${ }^{[4]}$. The antibacterial effects of sudanese honey were compared to those of five antibiotics - ampicilline, cephadrine, chloramphenicol, gentamicin and oxytetracycline. Undiluted honey was tested against the pathogens Bacillus subtilis, S. aureus, E.coli, Klebsiella aerogens and Pseudomonas aeruginosa. All honey tested were inhibitory against all these bacteria but gentamicin was the only antibiotic effective against P. aeroginosa ${ }^{[4]}$. A recent study documented the sensitivity of multiresistant strains of Burkholderia cepacia to manuka honey at concentrations below 6 percent. B. cepacia causes pulmonary infections in cystic fibrosis. Suggested clinical applications for treating B. cepacia with honey include honey aerosols as an adjunct to antibiotic therapy and topically for superficial infections and wounds.

Anti-inflammatory and antiviral effects of honey

Honey has a direct anti-inflammatory effect on wounds, especially not only as a secondary effect resulting from the antibacterial action removing the bacteria that cause inflammation ${ }^{[12]}$. Nitric oxide (NO) metabolites, nitrite and nitrate, were identified in various honeys ${ }^{[41]}$. NO has antiviral effects against the DNA and RNA of several viruses ${ }^{[22]}$. There is some evidence of NO activity directly or indirectly blocking HIV-1 replication ${ }^{[42]}$. The presence of NO metabolites in honey and the ability of honey to increase NO production in various biological fluids may explain the potent biological effects $^{[43,44]}$. Different studies found a benefit in treating herpes labialis with medical honey ${ }^{[39,40]}$.

Animal studies prooving the healing quality of honey

Many studies have been performed on the effectiveness of honey in promoting the healing of standardized wounds created on experimental animals. These experiments not only have allowed there to be much more closely comparable controls in trials but also have allowed histological examination of the healing wounds to provide additional data besides the usual measurements of decrease in wound size and time to heal. In a study 24 male mice were operated with skin excision of the neck region, in which $50 \%$ of the animals had pure honey applied in a thin layer to the wounds twice daily, while the control group had saline applied at the same frequency and time of day. Honey-treated mice had a greater thickness of granulation tissue in the centre of the wounds, compared to the control mice ${ }^{[5]}$. In another study, deep skin burns were applied in twelve places on the flanks of three pigs. The study compared the efficacy of honey to sugar solutions, both of very similar carbohydrate composition and concentration, and silver sulfadiazine in healing burn tissue ${ }^{[6]}$. Honey and sugar both produced more rapid healing than did silver sulfadiazine, with wounds closing within 21 days for honey and sugar, but requiring 28-35 days for silver sulfadiazine. The mechanism by which honey produced a more rapid and effective healing than either sugar or silver sulfadiazine was not identified, although tissue treated with sugar showed more myofibroblasts than did the honey-treated tissue. Based upon the theory of wound healing, honey may cause less hypertrophic scarring ${ }^{[27]}$. 
Potential safety risks of honey in children

Mad honey poisoning, allergy to honey, infant botulism and pain are the most known complications following honey intake.

Mad honey poisoning: In cases of mad honey poisoning bradycardia, cardial rhythm disturbances like bradycardia or atrioventricular block, convulsions, vomiting, sweating, blurred vision, chills and cyanosis are known ${ }^{[35,47]}$. Especially honey from the Black Sea region contain grayanotoxin I, which is responsible for honey poisoning ${ }^{[47]}$. Different forms of grayanotoxins have been isolated from the leaves and flowers of the rhododendron and some other plants ${ }^{[47]}$. Animal studies showed that grayanotoxin I increases the membrane permeability to sodium in sodium dependent excitable membranes and maintains those cells in a state of depolarisation ${ }^{[49,50]}$.

Allergy to honey: Honey allergy is not common but is well recognized and can result in anaphylaxis. Allergy may be due to both plant and bee proteins and pollen found in the honey. Infant botulism is a rare condition caused by contamination of honey with spores of Clostridia. Honey appears to be one commonly-implicated dietary source of Clostridium spores. It occurs mainly in infants less than 12 months of age, nearly $95 \%$ of cases found in the first 6 months of life.

Infant botulism: No case of topical medical honey application was found in literature to induce infant botulism. Germinating spores of clostridia are colonized in the gut of the infant after oral intake, leading to constipation as the first sign of botulism. Concerns about wound infection from Clostridium spores appear unfounded, as no such complication has been described in more than 500 reports in the literature ${ }^{[31]}$.

Pain: Some patients experience pain on application of honey. In these cases a correlation between concentration of honey and the level of pain seems to be present; higher concentrations of honey seem to induce a higher level of pain ${ }^{[36,37]}$, whereby the high osmotic potential (drawing pain) and/or low $\mathrm{pH}$ may be causal. Nevertheless, pain issues do not appear to exert a negative effect on healing rates but can influence patient life quality, depending on their tolerance. In a study comparing aciclovir vs. honey in treating labial herpes, a significant lower pain duration was found in the honey group ${ }^{[40]}$. These findings were found in adult population, but to date never analysed in children.

\section{Discussion}

An ideal wound antiseptic would meet the following four criteria: first. fast onset of bactericidal action, second. enhancement and acceleration of the physiologic process of wound healing, third. no adverse local or systemic effects and fourth. moderate costs.

Normal wound healing is a tightly regulated dynamic process in which the activity of several factors and cytokines is precisely co-ordinated. There is a great interest within the area of chronic wound management for products with an antibacterial and anti-inflammatory quality such as honey.

Topical honey treatment has been shown to possess antimicrobial properties, promote autolytic debridement, stimulate growth of wound tissues to hasten healing and to start the healing process in dormant wounds, stimulate anti-inflammatory activity that rapidly reduces pain, oedema and exudate production.

Many comparative studies have been set up and more data are available on the new generation of 'medical device grade'honey products ${ }^{[18,19,32,33]}$. Gamma-irradiated „medical honey“ is available, which has also been selected for the potent antibacterial properties, although most of the cases in the medical literature have used raw honey ${ }^{[18,19,38]}$. Medihoney ${ }^{\mathrm{TM}}$ has been one of the first medically certified honeys licensed as medical devices for professional wound care in Europe, the United States (FDA approval) and Australia ${ }^{[31,54]}$.

Although the mechanism by which honey speeds up the healing process have not been determined. Some findings provide possible explanations: One way in which honey may work is through the stimulation of an inflammatory response in leukocytes ${ }^{[57-59]}$, as inflammation is what triggers the cascade of cellular events that give rise to the production of growth factors which control angiogenesis and proliferation of fibroblasts and epithelial cells. Recently, Tonks discovered a 5.8kDA component of manuka honey which stimulates the production of TNF-" in macrophages via 
Toll-like receptor $4^{[59]}$.

Another mechanism concentrates on the low pH-level of honey (3.4-5.5; mean 4.4) ${ }^{[60]}$. Wound healing situations are often accompanied by $\mathrm{pH}$-values of 7.3 in wound exsudates. Yet, this is also the $\mathrm{pH}$ range within which proteases have their optimum activity and reducing the $\mathrm{pH}$ of the wound environment through the application of medical honey may reduce the activity of these, thereby facilitating tissue regeneration. Many hypotheses of the healing mechanism of honey have been stated. To date, none of these have been confirmed with certainty. Obviously, parameters such as creation of a moist wound environment, antibacterial effects and low pH play a role, however. Further intensive molecular research is necessary.

When evaluating clinical evidence it is important to rank the available information according to current standards. Thus, randomised controlled trials are mentioned as the highest level of clinical evidence. Case studies are commonly seen to have limited value ${ }^{[16-19]}$. In a systematic review in the use of honey as a wound dressing carried out by Gethin, conclusion was that there is a lack of high quality comparative evidence for both conventional and unconventional treatments like honey ${ }^{[13]}$. This study suggest that time to healing was significantly shorter for honey but study quality was poor. The review concludes that confidence in the conclusion that honey is a useful treatment for superficial wounds or burns is low. This study concluded that the evidence available from seven comparative studies on 264 patients was limited by lack of blinding, poor reporting and poor validity. Different authors argued that there was a need for more than one robust randomised controlled trial to support the use of honey ${ }^{[13-15,19]}$. Critically, a study evaluated the effectiveness of honey-impregnated gauzes, hydrocolloid dressings and saline-soaked gauze for the treatment of skin graft donor sites ${ }^{[30]}$. No significant difference was found between hydrocolloid and honey impregnated gauze with regard to time to healing and pain ${ }^{[30]}$. In this trial, honey was compared with 3 controls, saline-soaked gauze, paraffin gauze, and a hydrocolloid. The significantly faster healing rate and lower pain scores achieved with honey compared with saline-soaked gauze and paraffin gauze clearly would have been due to physical effects of the honey and not to psychosomatic effects ${ }^{[30]}$. In a randomized controlled trial published in 2007 by Jull, honey-impregnated dressings did not significantly improve venous ulcer healing at 12 weeks compared with usual care ${ }^{[45]}$. It should be noted, however, that statistical significance in comparative trials of wound dressings is rarely obtained. Many studies showed beneficial effect in treating viral diseases and MRSA with honey ${ }^{[38-42,47,48,51-53]}$. In these references, most often case studies were reported; statistical significance was lacking.

To date, there has been little information treating pediatric patients with honey for wound management. Only few case reports and few controlled randomized trials do exist for the pediatric population $\left.{ }^{[18,19}\right]$. The scientific evidence for using conventional wound care products especially in paediatric patients is poor. No prospective randomized studies have been performed in this particular population.

The results of Simon, dealing with wound care with antibacterial honey (Medihoney) in pediatric hematology-oncology are promising ${ }^{[19]}$.

Simon reported recently, that a pediatric patient with acute myeloic leukemia and wound infection with methicillin-resistant coagulase-negative staphylococci received topical medical honey application, leading to a successful healing without local or systemic complications. In a survey published in 2006, 15 pediatric oncology patients with different oncologic diseases were successfully treated with MedihoneyTM(19). An internet-based documentation system with standardized items for the documentation of wound healing in children will be initiated in a pediatric oncology center having a 4-year experience with Medihoney ${ }^{\mathrm{TM}[19]}$. The main objective of this database will be the cumulative analysis of prospectively documented treatment experiences from many participating centers including pediatric and adult patients.

In conclusion, the above information shows that in microbiological and clinical tests, honey offers many advantages in controlling bacterial growth and in the treatment of certain health problems like gastric ulcers, burn wounds, leg ulcers and wounds in pediatric patients.

Low costs, antibacterial and antiviral effects and the absence of antibiotic resistance development as found in 
conventional antibiotics are important advantages in treating pediatric patients with honey. In industrial countries and also in countries where millions of people are still struggling below the poverty line, honey offers a cost-effective therapy to treat pediatric wound infections. Disadvantages of topical honey application may appear in children with known but rare allergy to honey and the development of potential pain episodes. No single case report in the literature of C.botulinum wound infection was found through treatment with irradiated medical honey.

First clinical studies were performed in pediatric oncology patients. The use of medical honey in pediatric day-care centers as the primary wound management should be recommended.

But to date, guidelines for the use of honey in pediatric wound care do not exist. Especially due to the little experience with pediatric patients, in the near future extensive randomized controlled trials should be performed to develop clear guidelines for pediatric wound management. The few studies deal with honey and pediatric wound management show promising results.

Taking all these facts and mentioned studies into account, the topical application of honey for wound care in children appears to have a high potential but leaves, to date, a few questions open. Further intensive research in this interesting field of wound management is necessary.

\section{References}

1. Tan ST, Wilkins AL, Molan PC, et al. A chemical approach to the determination of floral sources of New Zealand honeys.Journal of Agricultural Research 1989; 28(4): 212-22.

2. Allen KL, Molan PC, Reid GM. A survey of the antibacterial activity of some NewZealand honeys. Journal of Pharmacy and Pharmacology 1991; 43: 817-22.

3. Willix DJ, Molan PC, Harfoot CG. A comparison of the sensitivity of wound-infecting species of bacteria to the antibacterial activity of manuka honey and other honey. Journal of Applied Bacteriology 1992; 73: 388-94.

4. White JW, Reithof ML, Subers MH, et al. Composition of American honeys. US Dept Agr Tech Bull 1962; 1261: 1-124.

5. Bauer L, Kohlich A, Hirschweir R, et al. Food allergy to honey: pollen or bee products? Characteriziation of allergenic proteins in honey by means of immunoblotting. J Allergy Clion Immunol 1996; 97 (1): 65-73.

6. Postmes TJ, Bosch MMC, et al. Speeding up the healing of burns with honey. In: Mizrahi A, Lensky Y 8eds), Bee Products: Properties, applications and apitherapy. New York, Plenum Press 1997; 27-37.

7. Molan PC. The antibacterial properties of honey. Chem in NZ 1995;10-14.

8. Zumla A, Lulat A. Honey-aremedy rediscovered. J Royal Soc Medicine 1989; 82: 384-5.

9. Beck BF, Smedley D. Honey and your health. 2nd edn., New York: Mc Bride, 1944

10. Molan PC. Why honey is effective as a medicine?-the scientific explanation of the effects. In Honey and healing (Munn P, Jones R eds). International Bee Research Association 2001.

11. Moore OA, Smith A, Campbell F, et al. A systematic review of the use of honey as a wound dressing. BMC Complementary and Alternative Medicine 2001; 1(1) 2.

12. Fox C. Honey as a dressing for chronic wounds in adults. British Journal of Community Nursing 2002; 10: 530-534.

13. Gethin G. Is there enough clinical evidence to use honey to manage wounds? Journal of Wound Care 2004; 7: 275-278.

14. Cooper RA, Molan PC, Krishnamoorty L, et al. Manuka honey used to heal a recalcitrant surgical wound. Eur J Clin Microbiol Infect Dis 2001; 20 (10): 758-759.

15. Dixon B. Bacteria can`t resist honey. Lancet Infect Dis 2003; 3 (2): 116.

16. Lusby PE, Coombes A, Wilkinson JM. Honey: a potent agent for wound healing? J Wound Ostomy Continence Nurs 2002; 29 (6): 295-300.

17. Molan PC. Potential of honey in the treatment of wound and burns. Am J Clin Dermatol 2001; 2 (1): 13-9.

18. Sofka K, Wiszniewsky G, Blaser G, et al. Antibakterieller Honig (Medihoney TM) zur Wundpflege-Wundantisepsis bei pädiatrischen Patienten in der Hämatologie-Onkologie? Krh Hyg Inf verh 2004; 26 (5): 183-7.

19. Simon A, Sofka K, Wizniewsky G, et al; . Wound care with antibacterial honey (Medihoney) in pediatric hematology-oncology. Support Care Cancer 2006; 14: 91-97.

20. Johnson DW, van Eps C, Mudge DW, et al. Randomized, controlled trial of topical exit-site application of honey (Medihoney) versus mupirocon for the prevention of catheter-associated infections in hemodialysis patients. J Am Soc Nephrol 2005; 16: 1-7. 
21. White JW, Reithof ML, Subers MH, et al. Composition of american honeys. US Dept Agr Tech Bull 1962; 1261: $1-124$.

22. White JW, Hoban N. Composition of honey, identification of disaccharides. Arch Biochem Biophys 1959; 80: 386-392.

23. Siddiqui IR, Furgala B. Isolation and characterization of oligosaccharides (Trisaccharides) from honey. J Apc Res 1968; 7: 51-59.

24. Wood B, Rademaker M, Molan P. Manuka honey, a low cost leg ulcer dressing. New Zealand Medical Journal 1997; 110(1040): 107.

25. Lawrence JC. Honey and wound bacteria. Editorial. Journal of Wound Care 1999; 8 (4):155.

26. Thomas S. Wound management and dressings. The Pharmaceutical Press.

27. Ambrose U, Middleton K, Seal D. In vitro studies of water activity and bacterial growth inhibition of sucrose-polyethylene glycol 400-hydrogen peroxide pastes used to treat wounds. Antimicrobial Agents Chemotherapy 1991; 35(9): 1799-1803.

28. Booth S. Are honey and sugar paste alternatives to topical antiseptics? Journal of Wound Care 2004; 13(1): 31-3.

29. Topham J. Why do some cavity wounds treated with honey or sugar paste heal without scarring? Journal of Wound Care 2001; 11(2): 53-55.

30. Mirsirlioglu A, Eroglu S, Karacaoglan N, et al. Use of honey as an adjunct in the healing of split thickness donor site. Dermatologic Surgery 2003; 29(2): 168- 172.

31. Molan PC. Clinical usage of honey as a wound dressing: an update. J Wound Care 2004; 13(9): 353-6.

32. Marshall C, Queen J, Manjooran J. Honey vs povidone iodine following toenail surgery. Wounds 2005; 1(1): 10-18.

33. Bangroo AK, Khatri R, Chauban S. Honey dressing in pediatric burns. J Indian Assoc Pediatr Surg 2005; 10(3): 172-5.

34. Dustman JH. Antibacterial effect of honey. Apiacta 1979; 14: 7-11.

35. Akinci S, Arslan U, Karakurt K. Cengel A. An unusual presentation of mad honey poisoning: Acute myocardial infarction. Int J Cardiol Sep 20 (Epub ahead of print)

36. Mphande AN, Killowe C, Phalira S, et al. Effects of honey and sugar dressings on wound healing. J Wound Care 2007; 16(7): 317-9.

37. Ozlugedik S, Genc S, Unal A, et al. Can postoperative pains following tonsillectomy be relieved by honey? A prospective, randomized, placebo controlled preliminary study. Int J Pediatr Otorhinolaryngol 2006; 70(11): 1929-34.

38. Blaser G, Santos K, Bode U, et al. Effect of medical honey on wounds colonised or infected with MRSA. J Wound Care 2007; 16(8): 325-8.

39. Holzgreve H. Honey is better than aciclovir in herpes. MMW Fortschr Med 2005; 147(3): 18.

40. Al-Waili N. Topical honey application vs. Acyclovir for the treatment of recurrent herpes simplex lesions. Med Sci Monit 2004; 10(8): MT94-98.

41. Al-Waili N. Identification of nitric oxide metabolites in various honeys: Effects of intravenous honey on plasma and urinary nitric oxide metabolites concentrations. J Med Food 2003; 6: 359-64.

42. Torre D, Pugliese A, Speranza F. Role of nitric oxide in HIV-1-infection: friend or foe? Lancet Infect Dis 2002; 2 : 273-80.

43. Al-Waili N. Effects of honey ingestion on nitric oxide in saliva. FASEB J 2003; 17: A767

44. Al-Waili N, Boni N. Effect of honey on blood and urinary nitric oxide in normal individuals. FASEB J 2003; 17 : A660

45. Jull A, Walker N, Parag V, et al. on behalf of the honey as Adjuvant Leg Ulcer Therapy trial collaborators. Randomized clinical trial of honey-impregnated dressings for venous leg ulcers. Br J Surg 2007; 95(2): $175-182$.

46. Vardi A, Barzilay Z, Linder N, et al. Local application of honey for treatment of neonatal postoperative wound infection. Acta Paediatr 1998; 87(4): 429-32.

47. Dilber E, Kalyoncu M, Yaris N, et al. A case of Mad Honey Poisoning presenting with convulsion: Intoxication instead of alternative therapy. Turk J Med Sci 2002; 32: 361-2.

48. Natarajan S, Williamson D, Grey J, et al. Healing of an MRSA-

colonised, hydroxyurea-induced leg ulcer with honey. J Dermatol Treat 2001; 12(1): 33-6.

49. Narahishi T, Seyama I. Mechanism of nerve membrane depolarization caused by grayanotoxin I. J Physiol 1974; 242: 471-478.

50. Seyama I, Narahishi T. Modulation of sodium channel of squid nerve membranes by grayanotoxin I. J Pharmacol Exp Ther 1981; 219: 614-24.

51. Lusby PE, Coombes AL, Wilkinson JM. Bactericidal activity of different honeys against pathogenic bacteria. Arch Med Res 2005; 36:464-7.

52. Cooper RA, Molan PC, Harding KG. The sensitivity to honey of gram-positive cocci of clinical significance isolated from wounds. J Appl Microbiol 2002; 93: 857-63. 
53. Cooper RA, Molan PC, Harding KG. Antibacterial activity of honey against strains of Staphylococcus aureus from infected wounds. J R Soc Med 1999; 92: 283-5.

54. Molan PC: The evidence supporting the use of honey as a wound dressing. Int J Low Extrem Wounds 2006; 5:40-2.

55. Bang LM, Buntting C, Molan P. The effect of dilution on the rate of hydrogen peroxide production in honey and implications for wound healing. J Altern Complement Med 2003; 9: 267-73.

56. Tonks AJ, Cooper RA, Jones KP, et al. Honey stimulates inflammatory cytokine production from monocytes. Cytokine 2003; 21: 242-7.

57. Tonks A, Cooper RA, Price AJ, et al.. Stimulation of TNF-alpha release in monocytes by honey. Cytokine 2001; 14: $240-2$

58. Abubarfeil N, Al-Oran R, Abo-Shehada M. The effect of bee honey on proliferative activity of human B- and T-lymphocytes and the activity of phagocytes. Food Agri Immunol 1999; 11: 169-77.

59. Tonks AJ, Dudley E, Porter NG, et al.. A 5,8-kDa component of manuka honey stimulates immune cells via TLR4. J Leukoc Biol 2007; 82: 1147-55.

60. Molan PC. The antibacterial activity of honey. The nature of the antibacterial activity. Bee World 1992; 73: 5-28. 